\section{Anthocyanin Pigment and Total Phenolic Content of Three Vaccinium Species Native to the Pacific Northwest of North America}

\author{
Jungmin Lee \\ Oregon State University, Department of Food Science, Corvallis, OR, 97331
}

\section{Chad E. Finn}

U.S. Department of Agriculture, Agricultural Research Service, HCRL, Northwest Center for Small Fruit Research, 3420 NW Orchard Avenue, Corvallis, OR 97330

\section{Ronald E. Wrolstad ${ }^{1}$ Oregon State University, Department of Food Science, Corvallis, OR, 97331}

Additional index words. Ericaceae, huckleberry, total monomeric anthocyanins, total phenolics, fruit breeding, blueberry breeding

\begin{abstract}
The total anthocyanin and total phenolic content of wild (samples from 4 populations) and cultivated (samples from 32 populations) Pacific Northwestern American Vaccinium species ( . membranaceum, $V$. ovalifolium, and $V$. deliciosum) were evaluated. The total monomeric anthocyanin content of all huckleberry samples analyzed ranged from 101 to $400 \mathrm{mg} / 100 \mathrm{~g}$ (expressed as cyanidin-3-glucoside), and the total phenolics varied from 367 to $1286 \mathrm{mg} / 100 \mathrm{~g}$ (expressed as gallic acid). Cluster analysis separated the samples into four different groups based on their anthocyanin and total phenolic content. Two groups had greater anthocyanin pigment and total phenolics; one consisted entirely of cultivated $V$. ovalifolium (LIG10, VAC485, VAC487, LIG33, LIG9, LIG2, and VAC349) and the other consisted of just cultivated $V$. membranaceum (LIG25). Significant variations in total anthocyanins, total phenolics, and the ratio of the total anthocyanins and total phenolics were observed among the different $V$. membranaceum, $V$. ovalifolium, and $V$. deliciosum populations cultivated in the Willamette Valley, Ore. The profile of the individual anthocyanins of the wild $V$. membranaceum, wild $V$. ovalifolium, and $V$. corymbosum 'Rubel' were conducted by high-performance liquid chromatography. The chromatograms of $V$. membranaceum, V. ovalifolium, and 'Rubel' were distinctly different in the amounts of delphinidin, cyanidin, and malvidin glycosides.
\end{abstract}

The current interest in the possible health benefits of antioxidants has led many investigators to characterize, and determine the quantities of the antioxidants in many small fruit crops (Kähkönen et al., 2001; Moyer et al., 2002; Wada and Ou, 1992). Blueberries (Vaccinium) were one of the first berry crops to receive a great deal of attention in part due to the longstanding recognition that consuming V. myrtillus L. (bilberry) fruit or extracts had health benefits (Kalt and Dufour, 1997). The high antioxidant capacity of blueberries has been highly correlated to their anthocyanin and total phenolic content (Kalt and Dufour, 1997; Kalt et al., 2000; Prior et al., 1998).

The NorthAmerican Pacific Northwest has

\begin{abstract}
Received for publication. Accepted for publication. We would like to thank the USDA-Forest Service for permission and advice in the process of collecting seed from National Forests in Oregon and Washington, and the USDA-Agricultural Research Service National Clonal Germplasm Repository for access to their seed collections for many of the populations grown in this study. We would also like to thank Mark Redhead for his help in numerous aspects of this project.

${ }^{1}$ To whom reprint requests should be addressed; e-mail Ron.Wrolstad@orst.edu.
\end{abstract}

12 to 14 native species of Vaccinium, depending on taxonomic interpretation (Hitchcock and Cronquist, 1973; Vander Kloet, 1988). The fruits of these species are commonly referred to as huckleberries in the region, as are the fruit of a number of wild Vaccinium species in eastern North America. Both of these groups are distinct from the true huckleberries, species of which belong to the genus Gaylussacia L. Three of the Pacific Northwest Vaccinium species-V. membranaceum Douglas ex Torrey, V. ovalifolium Smith, and V. deliciosum Piper-are commonly harvested from native stands for home consumption or commercial sale. In addition, in Pacific Northwest Native American cultures, huckleberries have medicinal and spiritual value beyond that of food (Moerman, 1998). These three species are in the Vaccinium section Myrtillus along with the bilberry, V. myrtillus L. (Vander Kloet, 1988). Vaccinium deliciosum and V. membranaceum are tetraploid, like cultivated highbush blueberry, while $V$. ovalifolium occurs in both diploid and tetraploid forms.

The cultivated blueberries in the section Cyanococcus produce several fruit in a cluster from each inflorescence bud. An abscission zone forms between each individual fruit and its pedicel (Vander Kloet, 1988). Nearly all of the anthocyanins are in the fruit skin. Vaccinium species in the section Myrtillus produce one to two fruit per bud, with no abscission zone between the individual fruit and pedicel, and the flesh and berry skin contains anthocyanins. The nonclustering fruiting habit of section Myrtillus species makes harvesting laborintensive and the tearing of the skin near the pedicel makes the fruit extremely perishable. The reliance on native stands for production means that the crop is subject to the vagaries of that year's environmental conditions. To have a more reliable crop, farmers are interested in commercializing Pacific Northwest huckleberry production in cultivated plantings. The potential of introgressing the fruit quality characteristics of the native species into commercially cultivated blueberries is also being pursued by the U.S. Department of Agriculture-Agricultural Research Service (USDA-ARS) in Corvallis, Ore. (C. Finn, personal communication), and by the University of Idaho in Sandpoint, Idaho (D. Barney, personal communication). Anthocyanin and phenolic content is an important criterion for identifying huckleberry populations suitable for breeding programs or commercialization.

Prior et al. (1998) studied 23 genotypes of four species (V. corymbosum L., V.ashei Reade, V. angustifolium Aiton, and V.myrtillus), Ehlenfeldt and Prior (2001) examined 87 Vaccinium corymbosum L. and hybrid genotypes, and Moyer et al. (2002) evaluated 30 genotypes of nine species (V. angustifolium, V. constablaei $x$ V. ashei, V. corymbosum, V. membranaceum, V. myrtilloides Michaux, V.ovalifolium, V. ovatum Pursh, and V. parvifolium Smith) and reported their total anthocyanins and phenolics. This study sampled 36 populations V. membranaceum, $V$. ovalifolium, and V. deliciosum to survey and compare the total anthocyanins and total phenolic contents of huckleberry fruit. Reference comparison was made with 'Rubel' highbush blueberry. 'Rubel' was originally selected from native $V$. corymbosum growing in New Jersey and was a prominent parent in the development of present-day cultivars (Hancock and Siefker, 1982).

\section{Materials and Methods}

Plant material. 'Rubel', commercial grade A, frozen blueberry samples were obtained from the Oregon Blueberry Commission and represent machine-harvested berries for 2001, by a commercial grower in the Willamette Valley. 'Rubel' fruit was used as a reference for this study. 'Rubel' fruit's new-found popularity with many processors is due to high pigment to volume content. The fruit for V. membranaceum, V. ovalifolium, and V. deliciosum were either harvested directly from wild stands (wild huckleberry samples) or were harvested from plants grown in Corvallis from seed collected from wild stands (cultivated huckleberry samples) (Finn and Young, 2002). The wild huckleberry samples $(n=4)$ from 1999 and 2001 were collected from one location in Oregon and two locations in Washington (Table 1). From each wild population, 
fully colored fruit were picked and stored on ice until they were frozen 1 to $3 \mathrm{~d}$ later. The cultivated huckleberries were harvested in 2002 from the USDA-ARS plantings in Corvallis). Cultivated huckleberries ( $\mathrm{n}=32$ populations) were harvested in June and July 2002 from 19 populations of $V$. membranaceum, 12 populations of $V$. ovalifolium, and one population of $V$. deliciosum. These samples were collected as seeds directly from the wild in 1993 and 1994, or through the USDA-ARS National Clonal Germplasm Repository. Thirty-two genotypes from each population were planted in a randomized complete block design with eight genotypes in each replication. Details of the original collection locations are provided (Table 1). The huckleberries were established in 1995, with standard highbush blueberry management practices. Fruit were collected from all cultivated huckleberry plants that produced ripe berries and samples were pooled by population. Berries representing a sample were collected from 1 to 10 genotypes per population (Table 1). Only one cultivated $V$. deliciosum produced fruit. The ripe berries were picked based on visual color and flavor.
Samples were picked and placed in an icebox and immediately frozen upon arrival at the laboratory (within $2 \mathrm{~h}$ of picking). All samples were kept frozen at $-70{ }^{\circ} \mathrm{C}$ until analysis.

Extraction. Anthocyanins and phenolics were extracted from frozen berries following the procedure described by Rodriguez-Saona and Wrolstad (2001). Samples were liquid nitrogen powdered using a mortar and pestle. Powdered sample $(6 \mathrm{~g})$ was sonicated with 12 $\mathrm{mL}$ of $100 \%$ acetone, followed by reextraction with $70 \%$ (v/v) aqueous acetone until the solution became colorless. It was then partitioned

Table 1. Locations, total monomeric anthocyanins (ACY), and total phenolic (TP) content of Vaccinium samples.

\begin{tabular}{|c|c|c|c|c|c|c|c|c|}
\hline Sample ${ }^{z}$ & Location & Year $^{y}$ & $\mathrm{ACY}^{\mathrm{x}}$ & $\mathrm{TP}^{\mathrm{w}}$ & $\mathrm{ACY} / \mathrm{TP}$ & CAA & Groups & $\begin{array}{l}\text { Genotypes/ } \\
\text { sample } \\
(\text { no. })^{\mathrm{v}}\end{array}$ \\
\hline \multicolumn{9}{|l|}{ Wild huckleberry $(\mathrm{n}=4)$} \\
\hline V. membranaceum ${ }^{\mathrm{u}}$ & Willamette Natl. Forest; Detroit Lake, Ore. & 1999 & 223 & 489 & 0.46 & $99 \mathrm{Vm}$ & 2 & --- \\
\hline V. membranaceum ${ }^{\mathrm{t}}$ & Gifford Pinchot Natl. Forest; Forlorn Lake, Wash. & 2001 & 201 & 511 & 0.39 & $1 \mathrm{Vm}$ & 2 & --- \\
\hline V. ovalifolium ${ }^{\mathrm{u}}$ & Gifford Pinchot Natl. Forest; Forlorn Lake & 2001 & 311 & 702 & 0.44 & $1 \mathrm{Vo}$ & 4 & --- \\
\hline V. delisciosum ${ }^{\mathrm{u}}$ & Gifford Pinchot Natl. Forest; Cultus Creek, Wash. & 2001 & 176 & 491 & 0.36 & $1 \mathrm{Vd}$ & 2 & --- \\
\hline Mean & & & 228 & 548 & 0.41 & & & \\
\hline $\mathrm{SD}$ & & & 59 & 103 & 0.05 & & & \\
\hline \multicolumn{9}{|c|}{ Cultivated huckleberry $(\mathrm{n}=32)$} \\
\hline \multicolumn{9}{|c|}{ V. membranaceum $(\mathrm{n}=19)$} \\
\hline VAC427 & Willamette Natl. Forest; Knutson Saddle, Ore. & 2002 & 157 & 571 & 0.27 & $2 \mathrm{Vm} 1$ & 2 & 3 \\
\hline VAC370 & Willamette Natl. Forest; Opal Lake, Ore. & 2002 & 143 & 555 & 0.26 & $2 \mathrm{Vm} 2$ & 2 & 7 \\
\hline VAC382 & Willamette Natl. Forest; Iron Mountain, Ore. & 2002 & 144 & 541 & 0.27 & $2 \mathrm{Vm} 3$ & 2 & 4 \\
\hline VAC368 & Deschutes Natl. Forest; Corbette State Park, Ore. & 2002 & 154 & 451 & 0.34 & $2 \mathrm{Vm} 4$ & 2 & 1 \\
\hline VAC432 & Deschutes Natl. Forest; Link Lake, Ore. & 2002 & 129 & 382 & 0.34 & $2 \mathrm{Vm} 5$ & 2 & 3 \\
\hline VAC426 & Deschutes Natl. Forest; Cabot Lake, Ore. & 2002 & 156 & 495 & 0.32 & $2 \mathrm{Vm} 6$ & 2 & 2 \\
\hline VAC425 & Rogue River Natl. Forest; Huckleberry Mountain, Ore. & 2002 & 122 & 582 & 0.21 & $2 \mathrm{Vm} 7$ & 2 & 3 \\
\hline VAC429 & Willamette Natl. Forest, Ore. & 2002 & 147 & 486 & 0.30 & $2 \mathrm{Vm} 8$ & 2 & 1 \\
\hline VAC423 & Olympics Natl. Forest; Mt. Washington, Wash. & 2002 & 190 & 527 & 0.36 & $2 \mathrm{Vm} 9$ & 2 & 2 \\
\hline VAC416 & Olympics Natl. Forest; Buck Mountain, Wash. & 2002 & 195 & 448 & 0.44 & $2 \mathrm{Vm} 10$ & 2 & 3 \\
\hline VAC398 & Gifford Pinchot Natl. Forest; La Wis Wis; Lily Lake, Wash. & 2002 & 101 & 706 & 0.14 & $2 \mathrm{Vm} 11$ & 4 & 3 \\
\hline VAC385 & Gifford Pinchot Natl. Forest; Wind River, Wash. & 2002 & 178 & 637 & 0.28 & $2 \mathrm{Vm} 12$ & 4 & 2 \\
\hline GP94-3-3 & Mount Rainier Natl. Park; Paradise, Wash. & 2002 & 212 & 530 & 0.40 & $2 \mathrm{Vm} 13$ & 2 & 3 \\
\hline GP94-4-2 & Gifford Pinchot Natl. Forest; Taklakh Lake, Wash. & 2002 & 113 & 367 & 0.31 & $2 \mathrm{Vm} 14$ & 2 & 1 \\
\hline GP94-6-1 & Gifford Pinchot Natl. Forest; Killen Creek, Wash. & 2002 & 146 & 512 & 0.29 & $2 \mathrm{Vm} 15$ & 2 & 1 \\
\hline LIG25 & Wenatchee Natl. Forest; east of Stevens Pass, Wash. & 2002 & 360 & 1286 & 0.28 & $2 \mathrm{Vm} 16$ & 1 & 2 \\
\hline \multirow[t]{2}{*}{ LIG29 } & Wenatchee Natl. Forest; between Steven Pass and & & & & & & & \\
\hline & Lake Wenatchee, Wash. & 2002 & 274 & 716 & 0.38 & $2 \mathrm{Vm} 17$ & 4 & 1 \\
\hline \multirow[t]{2}{*}{ LIG41 } & Gifford Pinchot Natl. Forest; Mt. Adams & & & & & & & \\
\hline & huckleberry fields, Wash. & 2002 & 127 & 371 & 0.34 & $2 \mathrm{Vm} 18$ & 2 & 1 \\
\hline VAC682 & Lolo Natl. Forest; Little Joe Creek, Mont. & 2002 & 151 & 642 & 0.24 & $2 \mathrm{Vm} 19$ & 4 & 1 \\
\hline Mean & & & 168 & 569 & 0.30 & & & \\
\hline $\mathrm{SD}$ & & & 61 & 201 & 0.07 & & & \\
\hline \multicolumn{9}{|l|}{ V. ovalifolium $(\mathrm{n}=12)$} \\
\hline VAC392 & Gifford Pinchot Natl. Forest; Clear Creek, Wash. & 2002 & 205 & 908 & 0.23 & $2 \mathrm{Vo} 1$ & 3 & 2 \\
\hline LIG12 & Mt. Baker-Snoqualmie Natl. Forest; Baker Lake, Wash. & 2002 & 225 & 752 & 0.30 & $2 \mathrm{Vo} 2$ & 4 & 5 \\
\hline LIG10 & Olympic Natl. Forest; North Pt., Wash. & 2002 & 300 & 888 & 0.34 & $2 \mathrm{Vo} 3$ & 3 & 7 \\
\hline VAC485 & Mt. Hood Natl. Forest; Burnt Lake, Ore. & 2002 & 354 & 1028 & 0.34 & $2 \mathrm{Vo} 4$ & 3 & 5 \\
\hline VAC487 & Willamette Natl. Forest; Cougar Reservoir, Ore. & 2002 & 244 & 897 & 0.27 & $2 \mathrm{Vo5}$ & 3 & 10 \\
\hline VAC344 & Willamette Natl. Forest; Salt Creek, Ore. & 2002 & 185 & 1054 & 0.18 & $2 \mathrm{Vo} 6$ & 3 & 4 \\
\hline LIG33 & Gifford Pinchot Natl. Forest; Packwood, Wash. & 2002 & 272 & 898 & 0.30 & $2 \mathrm{Vo} 7$ & 3 & 3 \\
\hline LIG9 & Olympic Natl. Forest; Mt. Muller, Wash. & 2002 & 327 & 1015 & 0.32 & $2 \mathrm{Vo} 8$ & 3 & 5 \\
\hline LIG2 & Olympic Natl. Forest; S.W. Quilcene, Wash. & 2002 & 400 & 1030 & 0.32 & $2 \mathrm{Vo} 9$ & 3 & 6 \\
\hline VAC349 & Willamette Natl. Forest; Quartz Creek, Ore. & 2002 & 263 & 994 & 0.26 & 2Vo10 & 3 & 1 \\
\hline LIG3 & Olympic Natl. Forest; Lord's Lake Loop, Wash. & 2002 & 201 & 693 & 0.29 & $2 \mathrm{Vo} 11$ & 4 & 1 \\
\hline LIG25 & Wenatchee Natl. Forest; east of Stevens Pass, Wash. & 2002 & 207 & 677 & 0.31 & $2 \mathrm{Vo} 12$ & 4 & 1 \\
\hline Mean & & & 265 & 903 & 0.29 & & & \\
\hline SD & & & 68 & 133 & 0.05 & & & \\
\hline \multicolumn{9}{|l|}{ V. deliciosum $(\mathrm{n}=1)$} \\
\hline VAC404 & Olympic Natl. Forest, Wash. & 2002 & 160 & 413 & 0.39 & $2 \mathrm{Vd} 1$ & 2 & 1 \\
\hline \multicolumn{9}{|c|}{ Highbush blueberry $(\mathrm{n}=1)$} \\
\hline V. corymbosum 'Rubel' & Willamette Valley, Ore. & 2001 & 230 & 738 & 0.31 & $\mathrm{R} 1$ & 4 & 1 \\
\hline
\end{tabular}

${ }^{\text {zVAC }}$ = USDA-ARS National Clonal Germplasm Repository (Corvallis, Ore.) accessions; LIG = collected by J. Luby, C. Finn, R. Harrison, and H. Hoover in 1993; GP = collected by C. Finn or D. Barney in 1993; ACY = total monomeric anthocyanin content; TP = total phenolic content; ACY/TP = the ratio of total monomeric anthocyanin content versus total phenolics; CAA = abbreviation of samples for cluster analysis; groups assigned by cluster analysis.

'Indicated the year of harvest.

${ }^{\mathrm{x}} \mathrm{ACY}$ was expressed as cyanidin-3-glucoside. Units were $\mathrm{mg} / 100 \mathrm{~g}$ of berries

wTP was expressed as gallic acid equivalents. Units were $\mathrm{mg} / 100 \mathrm{~g}$ of berries.

"Number of individual genotypes that represent the population. For the samples collected from the wild, numerous bushes, often over 100 were sampled. However, it was impossible in the field to determine if these "bushes" were genetically distinct.

"Fruit collected by J. Lee and M. Redhead in 1999.

'Fruit collected by C. Finn, B. Fick, E. Finn, and I. Finn in 2001. 


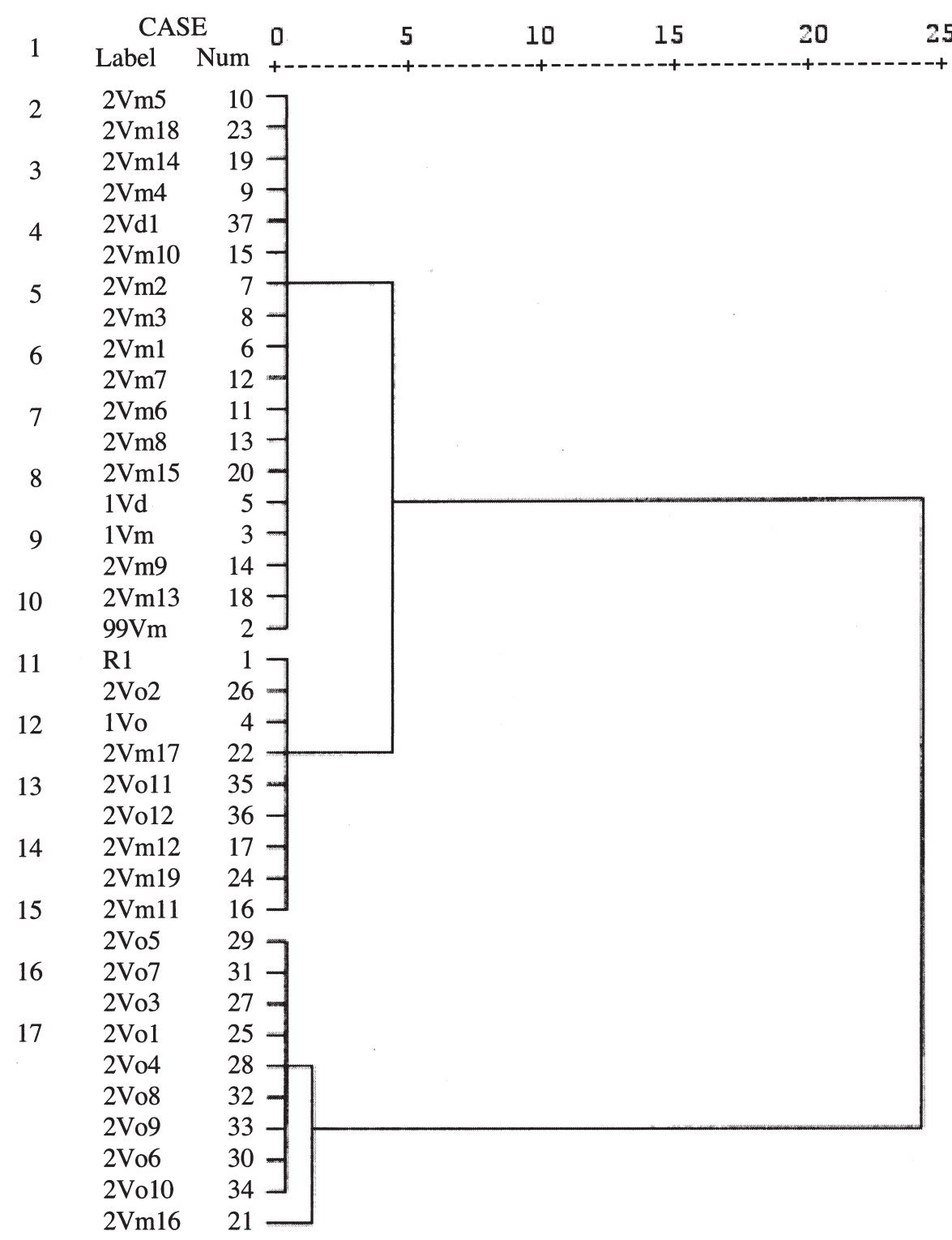

Fig. 1. Dendrogram from cluster analysis of 37 fruit samples of Vaccinium membranaceum, V. ovalifolium, $V$. deliciosum, and 'Rubel' analyzed for total ACY and TP. The sample names for the abbreviations are listed in Table 1.

with chloroform ( 1 acetone : 2 chloroform, by volume) to obtain the aqueous fraction. The aqueous portion was collected, and residual acetone present was evaporated by a Büchi rotovapor (Westbury, N.Y.) at $40{ }^{\circ} \mathrm{C}$. The aqueous extract was dissolved to a final volume of $25 \mathrm{~mL}$ with distilled water. Samples were then stored at $-70^{\circ} \mathrm{C}$ until analysis. Samples for anthocyanin separation by high -performance liquid chromatography (HPLC) were filtered through a $0.45-\mu \mathrm{m}$ Millipore filter type HA (Millipore Corp., Bedford, Mass.) before HPLC injection. Hewlett-Packard HPLC-2D ChemStation software was used for data analysis.

Determination of total anthocyanins and total phenolics. Total monomeric anthocyanins (ACY) were determined using the $\mathrm{pH}$ differential method (Giusti and Wrolstad, 2001). Absorbance was measured at 520 and $700 \mathrm{~nm}$. ACY was expressed as cyanidin-3-glucoside (molar extinction coefficient of $26,900 \mathrm{~L} \cdot \mathrm{cm}^{-1} \cdot \mathrm{mol}^{-1}$ and molecular weight of $449.2 \mathrm{~g} \cdot \mathrm{mol}^{-1}$ ). The unit for ACY was mg of anthocyanin/100 g of frozen berries. Total phenolics (TP) were measured by the Folin-Ciocalteu (FC) method (Waterhouse, 2002). Absorbance was measured at $765 \mathrm{~nm}$. TP was expressed as gallic acid equivalents. The unit for TP was mg of gallic acid/100 g of frozen berries. A UV-visible spectrophotometer (model 300; Shimadzu Inc., Kyoto, Japan) and 1-cm-pathlength cells were used for both measurements. Measurements of ACY and TP on sample extracts were replicated 2 times.

HPLC separation of anthocyanins. Anthocyanins were separated by reversed-phase HPLC using a Hewlett-Packard 1090 (Agilent Technologies Inc, Wilmington, Del.), equipped with a photodiode array detector. Absorbance spectra were recorded for all peaks. Flow rate was $1 \mathrm{~mL} \cdot \mathrm{min}^{-1}$ and injection volume was 20 $\mu \mathrm{L}$. Column temperature was maintained at $40{ }^{\circ} \mathrm{C}$. A Prodigy $5 \mu \mathrm{m}$ ODS (3) $100 \AA$ ( 250 $\times 4.6 \mathrm{~mm}$ ) column from Phenomenex was used (Torrance, Calif.). Solvent A was $100 \%$ acetonitrile. Solvent B was $10 \%$ (v/v) acetic acid and $1 \%(\mathrm{v} / \mathrm{v})$ phosphoric acid in water. All solvents were HPLC grade. The program used a linear gradient from $2 \%$ to $20 \%$ solvent $\mathrm{A}$ in $25 \mathrm{~min}$; then a linear gradient of solvent $\mathrm{A}$ from $20 \%$ to $40 \%$ in $5 \mathrm{~min}$, with simultaneous detection at 280, 320, and $520 \mathrm{~nm}$ (Durst and Wrolstad, 2001).

Statistical analyses. SPSS (Chicago, Ill.) version 11.0 was used for the statistical analyses. Pearson correlation and cluster analysis were performed on the ACY and TP results. Initially, hierarchical cluster analysis was performed using squared Euclidean distance and Ward method, then a dendrogram was made regarding the individual samples. From the dendrogram (Fig. 1), the decision was made to use four clusters. Four cluster solution was examined by K means cluster (to create cluster membership) and discriminant analysis (to check proper clustering). Differences among group means were tested using the Tukey honest significant difference (HSD) at $\alpha=0.05$ level.

\section{Results and Discussion}

Vaccinium membranaceum collected from a single location in the wild in 1999 had 223 $\mathrm{mg}$ of ACY/100 g (Table 1). Fruit collected from single regions for each of the three species in 2001 had an ACY content from 176 to $311 \mathrm{mg} / 100 \mathrm{~g}$; V. ovalifolium had the highest ACY, V. membranaceum was next, and $V$. deliciosum had the least. The ACY for the wild-collected $V$. ovalifolium sample was the only one higher than 'Rubel' (230 mg ACY/100 g, $738 \mathrm{mg} \mathrm{TP} / 100 \mathrm{~g}$ ). All four of the huckleberry samples collected from the wild had lower TP than 'Rubel'. Samples collected in the wild could not be frozen immediately, so some degradation of ACY and TP could have occurred during the 1 to $3 \mathrm{~d}$ storage on ice before freezing.

Samples from cultivated V. membranaceum had ACY contents ranging from 101 to 360 $\mathrm{mg} / 100 \mathrm{~g}($ mean $=168 \mathrm{mg} / 100 \mathrm{~g})$. Samples from cultivated $V$. ovalifolium had ACY contents ranging from 185 to $354 \mathrm{mg} / 100 \mathrm{~g}$ $($ mean $=265 \mathrm{mg} / 100 \mathrm{~g})$, which was similar to the values reported by Moyer et al. (2001). Only two samples (LIG25 and LIG29) of the 19 cultivated $V$. membranaceum samples had a higher ACY content than 'Rubel'. These two populations were originally collected from locations $\approx 9 \mathrm{~km}$ apart. Most ( 7 of 12 ) cultivated V.ovalifolium samples had greater ACY content than 'Rubel' (excluding VAC392, LIG12, VAC344, LIG3, and LIG25).

Total phenolic contents of cultivated V. membranaceum ranged from 367 to $1286 \mathrm{mg} / 100 \mathrm{~g}$ (averaged $569 \mathrm{mg} / 100 \mathrm{~g}$ ). LIG 25 was the only $V$. membranaceum sample that had more TP than 'Rubel' (43\% more). Cultivated V. ovalifolium TP content ranged from 677 to $1054 \mathrm{mg} / 100$ $\mathrm{g}$ [averaged $903 \mathrm{mg} / 100 \mathrm{~g}$, which was higher than the value reported by Moyer et al. (2002)]. Most (10 of 12) cultivated V. ovalifolium samples had a higher TP than 'Rubel' (excluding LIG3 and LIG25). The single cultivated $V$. deliciosum sample had a TP of $413 \mathrm{mg} / 100 \mathrm{~g}$. 


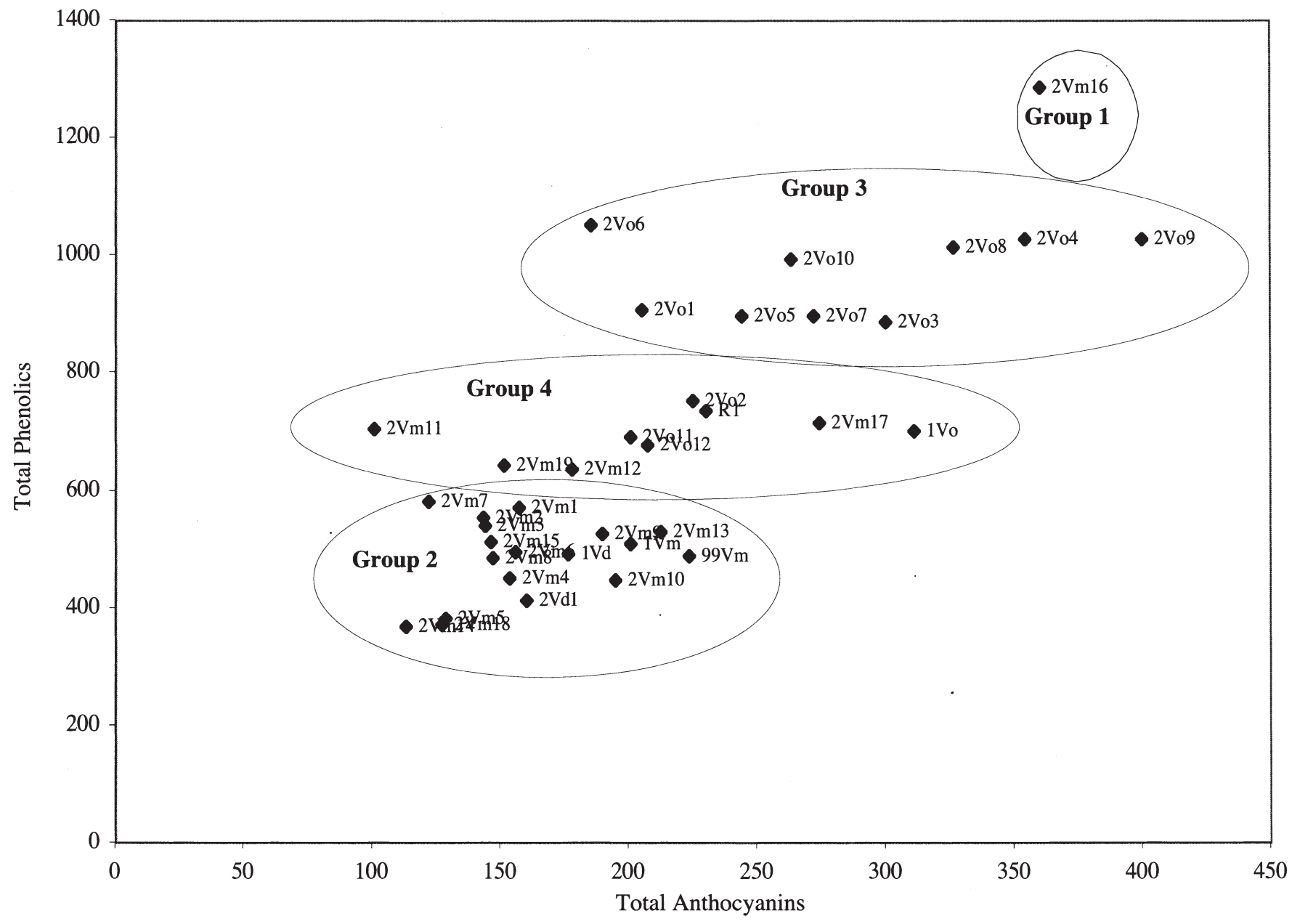

Fig. 2. Discriminant analysis of all berry samples $(\mathrm{n}=37)$ of Vaccinium membranaceum, V. ovalifolium, V. deliciosum, and 'Rubel', plotted TP versus ACY. Four clusters were obtained. The sample names corresponding to the abbreviations are listed in Table 1.

Table 2. The results of the Tukey HSD for the three groups obtained from the cluster analysis.

\begin{tabular}{lcccc}
\hline Group & No. of samples & ACY means & TP means $^{\mathrm{z}}$ & ACY/TP means $^{\mathrm{z}}$ \\
\hline 2 & 18 & $161 \mathrm{a}$ & $485 \mathrm{~A}$ & 0.34 aa \\
3 & 9 & $284 \mathrm{~b}$ & $968 \mathrm{~B}$ & $0.28 \mathrm{aa}$ \\
4 & 9 & $209 \mathrm{a}$ & $696 \mathrm{C}$ & $0.30 \mathrm{aa}$ \\
\hline
\end{tabular}

${ }^{2}$ Mean values with different superscript letters were significantly different at $P<0.05$.

The average of ACY/TP of the wild huckleberry $(0.41)$ samples were higher than the average ACY/TP of cultivated $V$. membranaceum (0.30), V. ovalifolium (0.29), and V. deliciosum (0.39) as well as 'Rubel' (0.31).

When ACY was plotted against TP (Fig. 2), some generalizations within species could be made. Two of the three $V$. membranaceum samples originally from the Wenatchee National Forest (LIG25 and LIG29) had the highest ACY and TP contents of any samples. Samples from three (LIG10, LIG9, and LIG2) of the four V. ovalifolium populations from the Olympic National Forest were among the highest for ACY and TP. The fourth sample (LIG3) from this region was among the lowest of all V. ovalifolium populations for these characters. The three $V$. ovalifolium samples (VAC487, VAC344, and VAC349) from the Willamette National Forest tended to have moderate ACY levels with fairly high TP levels. If variability for high ACY and TP content were targeted in germplasm collection or fruit harvest, the
Wenatchee National Forest, particularly the region around Stephens Pass and Wenatchee Lake should be collected for V. membranaceum, and the Olympic National Forest, particularly in the mountain range above the Strait of Juan de Fuca should be similarly collected for $V$. ovalifolium.

The correlation between the ACY and TP was $0.774(P<0.01)$. The huckleberry samples were divided into four distinct groups (or clusters) based on the cluster analysis (Fig. 2 and Table 2). There was $0 \%$ misclassification of the samples. Group 1 had one sample (LIG25, cultivated V. membranaceum) with a distinctly high ACY and TP. The original collection notes for the location (Wenatchee National Forest; east of Stevens Pass) of LIG25 indicated that the population had what appeared to be hybrids between $V$. ovalifolium and $V$. membranaceum, which might explain the high ACY and TP content. The seeds might have been collected from plants that appeared to have vegetative characteristics of
V. membranaceum, but fruit characteristics of V. ovalifolium. Also, the anthocyanin HPLC profile of LIG25 (Fig. 3D), the cultivated $V$. membranaceum, was distinctly different from the wild V. membranaceum samples (Fig. 3A) and other V. membranaceum (data not shown). LIG25's anthocyanin profile had elevated levels of the glucosides of delphinidin, cyanidin, petunidin, and malvidin (peaks 2, 5, 8, and 12) compared to the other V.membranaceum HPLC profiles. LIG25 had the anthocyanin profile that was more similar to $V$. ovalifolium (Fig. 3B). Group $2(\mathrm{n}=18)$ consisted of 14 cultivated $V$. membranaceum, two $V$. deliciosum samples (wild collected and cultivated VAC404), and both wild $V$. membranaceum samples. All of the cultivated $V$. membranaceum originally from Oregon were in group 2. Group $3(\mathrm{n}=$ 9) consisted only of cultivated V. ovalifolium. Group $4(n=9)$ contained 'Rubel', three cultivated V.ovalifolium (LIG12,LIG3, andLIG25), four cultivated V. membranaceum (VAC398, VAC385, LIG29, and VAC682), and the wild V. ovalifolium. Groups 1 and 3, which contains only cultivated huckleberries, appeared to have an overall higher ACY and TP than group 4, which contained 'Rubel'. All the huckleberries from the wild were either in group 2 or group 4. From the dendrogram, Group 1 (LIG 25, cultivated $V$. membranaceum) appeared to be an outlier and contained only one sample, so it 


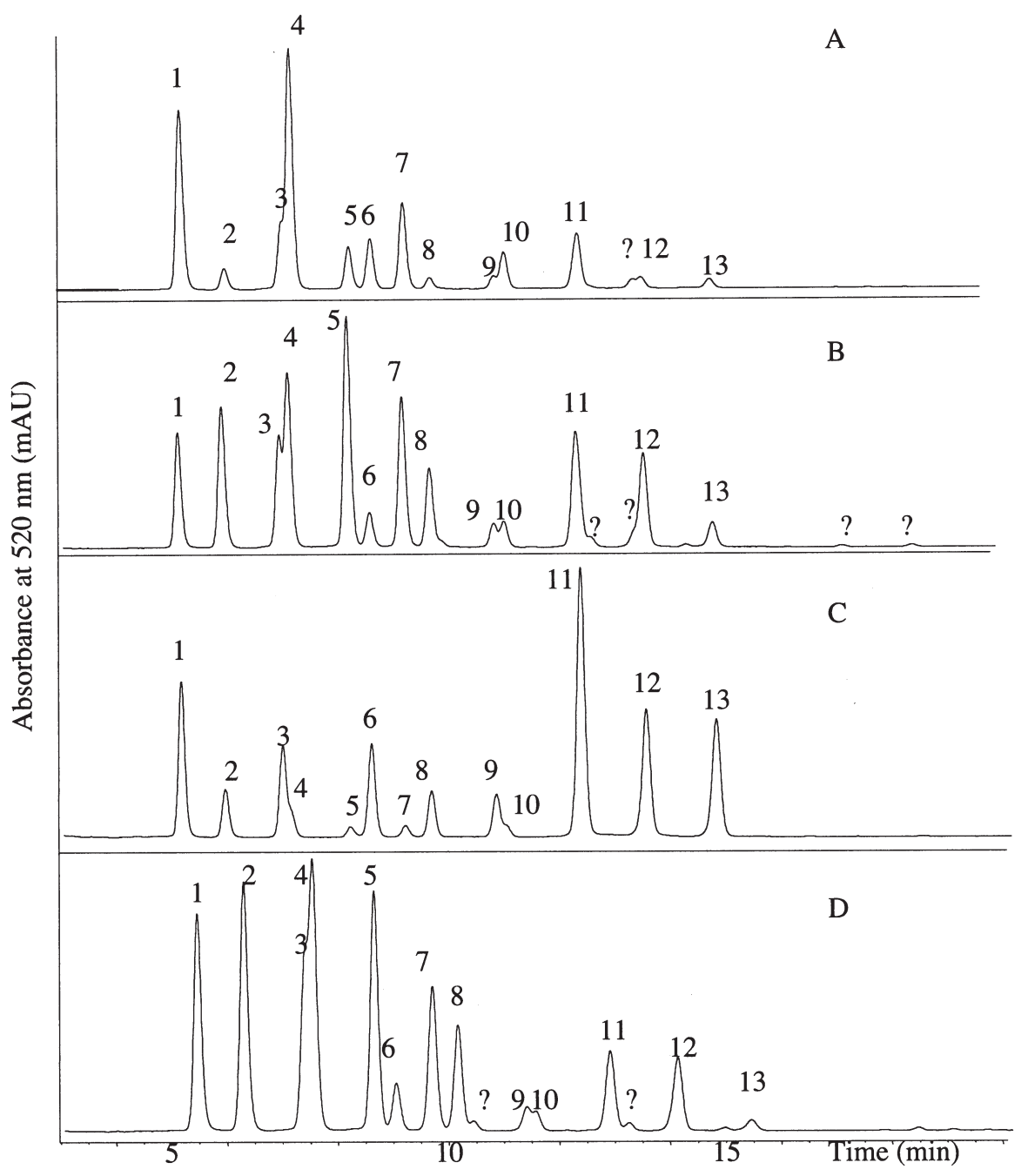

Fig. 3. Anthocyanin HPLC profiles of (A) wild Vaccinium membranaceum, (B) wild V. ovalifolium, (C) 'Rubel' ( $V$. corymbosum), and (D) LIG25 (cultivated V. membranaceum, the outlier). Tentative peak assignments: 1 = delphinidin-3-galactoside, 2 = delphinidin-3-glucoside, 3 = delphinidin-3-arabinoside, $4=$ cyanidin-3-galactoside, 5 = cyanidin- 3 -glucoside, 6 = petunidin- 3 -galactoside, $7=$ cyanidin -3 -arabinoside $8=$ petunidin-3-glucoside, $9=$ petunidin-3-arabinoside, $10=$ peonidin- 3 -galactoside, $11=$ malvidin- 3 galactoside, 12 = malvidin-3-glucoside, $13=$ malvidin- 3 -arabinoside, and $?=$ unknowns .

was not included in the Tukey HSD analysis. Groups 2, 3, and 4 had significantly different TP averages. ACY of group 2 was significantly different from group 3 but not group 4 . $\mathrm{ACY} / \mathrm{TP}$ values of group 2, 3, and 4 were not significantly different.

In this study, bilberry (Vaccinium myrtillus L.) was not available. Prior et al. (1998) reported bilberry containing $330 \mathrm{mg}$ of ACY/100 $\mathrm{g}$ and $525 \mathrm{mg}$ of TP/100 $\mathrm{g}$ (using the same methods). Three of the cultivated huckleberries, LIG25 (V.membranaceum), VAC485 (V.ovalifolium), and LIG2 (V. ovalifolium) of this study had higher ACY and TP content than bilberry. All of the cultivated $V$. ovalifolium samples had a higher TP content than bilberry, as did 11 of the 19 cultivated $V$. membranaceum samples. High TP values are important, as the major nonanthocyanin flavonoid present in blueberries is chlorogenic acid (Lee et al., 2002), and it has been proven to possess a strong antioxidant activity (Zheng and Wang, 2003). Also, blueberry research by Prior et al. (1998) and Moyer et al. (2002) has shown a higher correlation between antioxidant content and
TP than between antioxidant content and ACY. Wild and cultivated samples of $V$. deliciosum, and 'Rubel' had lower ACY and TP content than Prior et al. (1998) reported for V. myrtillus. Care should be exercised when making comparisons of the ACY content of berries with other reported values, as researchers may use different standard coefficients and molecular weights to calculate the ACY. Kähkönen et al. (2001) reported the anthocyanin and TP values of bilberry obtained from three different growing locations. The anthocyanin content ranged from 2298 to $3090 \mathrm{mg} / 100 \mathrm{~g}$ of dry matter (used HPLC) and the TP ranged from 3300 to $3820 \mathrm{mg} / 100 \mathrm{~g}$ of dry matter (used FC method). Also, researchers have reported variation in anthocyanin and phenolic contents in blueberry due to different growing season and environmental factors (Clark et al., 2002; Conner et al., 2002; Prior et al., 1998). Cultivated huckleberry samples examined in this paper were from one growing season and a single location. In addition, the number of fruit per plant in the current study was, in general, too low, often zero, to allow a comparison of within and among population variation as has been done in blueberry (Conner et al., 2002). Based on these studies in blueberry, one would expect within population to be significant, but nonetheless, the best populations are likely sources of genotypes with the greatest ACY or TP levels.

The peak assignments of separation of anthocyanins by HPLC (Fig. 3A-C.) were made according to their Ultraviolet (UV)-visible spectra and retention time. All samples were analyzed by HPLC, but only two chromatograms that represented the general anthocyanin profile of V. membranaceum and V. ovalifolium samples are included in this paper. Although $V$. membranaceum samples had a lower ACY compared to V. ovalifolium, the individual anthocyanin present was distinctly different when samples were examined by HPLC (Fig. 3A and B). The major anthocyanins present in V. membranaceum samples were cyanidin glycosides (cyanidin-3-galactoside >> cyanidin-3-arabinoside $>$ cyanidin-3-glucoside) and delphinidin glycosides (delphinidin-3-galactoside >> delphinidin-3-arabinoside $>$ delphinidin-3glucoside). Vaccinium membranaceum was low in malvidin glycosides. Vaccinium ovalifolium samples were high in delphinidin glycosides, cyanidin glycosides, and malvidin glycosides (galactoside, glucoside, and arabinoside of delphinidin, cyanidin, and malvidin were present in fairly even distribution). 'Rubel' was high in malvidin glycosides (galactoside, glucoside, and arabinoside of malvidin) and delphinidin glycosides (galactoside, glucoside, arabinoside of delphinidin), but low in the cyanidin glycosides. The qualitative analysis of anthocyanins agrees with identification work reported by Lee et al. (2002) and Ballington et al. (1987).

\section{Conclusion}

Samples from V.ovalifolium and V.membranaceum populations grown in the Willamette Valley showed significant variation among samples and between the two species for ACY content, TP content, and the ACY/TP ratio. Fruit of $V$. ovalifolium generally had higher ACY and TP contents than V. membranaceum and TP content higher than 'Rubel'. Vaccinium ovalifolium fruit are smaller than $V$. membranaceum, which may explain some of the differences between the two species. A blueberry breeding program that is trying to develop selections with high ACY and TP could initially target genotypes within the best populations for more in-depth characterization to identify the best genotypes of $V$. ovalifolium and $V$. membranaceum to use as a source of these traits although crossing barriers between sections Cyanococcus and Myrtillus are a continuing challenge.

\section{Literature Cited}

Ballington, J.R., W.E. Ballinger, E.P. Maness, and J.J. Luby. 1988. Anthocyanin, aglycone and aglycone-sugar content of the fruits of five species of Vaccinium section Myrtillus. Can. J. Plant Sci. 68:241-246.

Clark, J.R., L. Howard, and S. Talcott, S. 2002. 
Variation in phytochemical composition of blueberry cultivars and breeding seasons. Acta Hort. 574:203-207.

Conner, A.M., J.J. Luby, C.B.S. Tong, C.E. Finn, and J.F. Hancock. 2002. Genotypic and environmental variation in antioxidant activity among blueberry cultivars. Acta Hort. 574:209-213.

Durst, R.W. and R.E. Wrolstad. 2001. Unit F1.2: Anthocyanins. Separation and characterization of anthocyanins by HPLC, p. 1-13. In: R.E. Wrolstad (ed.). Current protocols in food analytical chemistry. John Wiley \& Sons, New York.

Ehlenfeldt, M.K. and R.L. Prior. 2001. Oxygen radical absorbance capacity (ORAC) and phenolic and anthocyanin concentrations in fruit and leaf of highbush blueberry. J. Agr. Food Chem. 49:2222-2227.

Finn, C.E. and A. Young. 2002. Variability for reproductive and vegetative traits in Vaccinium membranaceum. Acta Hort. 574:181-187.

Giusti, M. and R.E. Wrolstad. 2001. Unit F1.2: Anthocyanins. Characterization and measurement with UV-visible spectroscopy, p. 1-13. In: R.E. Wrolstad (ed.). Current protocols in food analytical chemistry. John Wiley \& Sons, New York.

Hancock J.F. and J.H. Siefker. 1982. Levels of inbreeding in highbush blueberry cultivars.
HortScience 17:363-366.

Hitchcock, C.L. and A. Cronquist. 1973. Flora of the Pacific Northwest. Univ. Wash. Press, Seattle.

Howard, L.R., J.R. Clark, and C. Brownmiller. 2003. Antioxidant capacity and phenolic content in blueberry as affected by genotype and growing season. J. Sci. Food Agr. 83:1238-1247.

Lee, J., R.W. Durst, and R.E. Wrolstad. 2002. Impact of juice processing on blueberry anthocyanins and polyphenolics: comparison of two pretreatments. J. Food Sci. 67:1660-1667.

Kähkönen, M.P.,A.I. Hopia, and M. Heinonen. 2001. Berry phenolics and their antioxidant activity. J. Agr. Food Chem. 49:4076-4082.

Kalt W. and D. Dufour. 1997. Health functionality of blueberries. HortTechnology 7:216-221.

Kalt W., J.E. McDonald, and H. Donner. 2000. Anthocyanins, phenolics, and antioxidant capacity of processed lowbush blueberry products. J. Food Sci. 65:390-393.

Moerman, D.E. 1998. Native American ethnobotany. Timber Press, Portland, Ore.

Moyer, R.A., K.E. Hummer, C.E. Finn, B. Frei, and R.E. Wrolstad. 2002. Anthocyanins, phenolics, and antioxidant capacity in diverse small fruits: Vaccinium, Rubus, and Ribes. J.Agr. Food Chem. 50:519-525.
Prior, R.L., G. Cao, A. Martin, E. Sofic, J. McEwen, C. O'Brien, N. Lischner, M. Ehlenfeldt, W. Kalt, G. Krewer, and C.M. Mainland. 1998. Antioxidant capacity as influenced by total phenolic and anthocyanin content, maturity, and variety of Vaccinium species. J. Agr. Food Chem. 46:2686-2693.

Rodriguez-Saona, L. and R.E. Wrolstad. 2001. Unit F1.1: Anthocyanins. Extraction, isolation and purification of anthocyanins, p. 1-11. In: R.E. Wrolstad(ed.). Current protocols in food analytical chemistry. John Wiley \& Sons, New York.

Vander Kloet, S.P. 1988. The genus Vaccinium in North America. Res. Branch Agr. Canada Publ. 1828.

Wada, L. and B. Ou. 2002. Antioxidant activity and phenolic content of Oregon caneberries. J. Agr. Food Chem. 50:3495-3500.

Waterhouse, A.L. 2002. Unit I1.1: Polyphenolics: Determination of Total Phenolics, p. 1-4. In: R.E. Wrolstad (ed.). Current protocols in food analytical chemistry. John Wiley \& Sons, New York.

Zheng, W. and S.Y. Wang. 2003. Oxygen radical absorbing capacity of phenolics in blueberries, cranberries, chokeberries, and lingonberries. J. Agr. Food Chem. 51:502-509. 